\title{
Some considerations on circular economy, municipal solid waste and occupational risk
}

\author{
Elena Cristina Rada $^{1 *}$, Irene Cestari ${ }^{2}$ and Elena Romenovna Magaril ${ }^{3}$ \\ ${ }^{1}$ Insubria University of Varese, Department of Theoretical and Applied Sciences, via G.B. Vico, 46, I- \\ 21100 Varese, Italy \\ ${ }^{2}$ University of Trento, Department of Civil, Environmental and Mechanical Engineering, via Mesiano \\ 77, 38123, Trento, Italy \\ ${ }^{3}$ Ural Federal University, Department of Environmental Economics, Mira str., 19, 620002, \\ Ekaterinburg, Russia
}

\begin{abstract}
The aim of the present article is to preliminarily analyse the effects that the introduction of the principles of circular economy can have on the occupational risk in the sector of MSW management. The chosen reference scenario concerns an Italian town that reached a very high efficiency of selective collection and where a lot of data have been generated in the last years to characterize the content of MSW. Since 2015, the town has to modify a few criteria of MSW management in order to fully comply with the vision of EU. The methodology adopted in the present article is based on the following steps. Details on the destination and material recovery were collected for each stream of MSW presently source separated: specifically, food waste and green waste, paper and cardboard, plastics, metals, glass, composite materials, textiles, expired medicaments, exhausted batteries and other. This scenario was analysed concerning new possible initiatives on source separated streams and their treatment (e.g. diapers). Moreover, additional modifications to the present approach were analysed in order to maximize material recovery, optimize energy recovery and minimize landfilling. Consequences of this reorganization of the sector have to be discussed in terms of occupational risk and economic impact.
\end{abstract}

\section{Introduction}

In the year 2015 the European Union (EU) issued an important package of documents on a new vision of Municipal Solid Waste (MSW) management, setting new specific targets on the valorization of the materials present in the generated stream [1-3].

The priority is material recovery [4-7]. Energy recovery from anaerobic digestion of source separated food waste is confirmed as integrated with material valorization (through post-composting) [8-10]. Landfilling must be reduced close to zero. The role of energy recovery from residual MSW (that is the MSW not source separated) has been clarified later by additional documents pointing out the need of assessing carefully the viability of

\footnotetext{
* Corresponding author: elena.rada@unitn.it
} 
constructing new dedicated plants (co-combustion of Solid Recovered Fuel, SRF, in cement factories allows both energy exploitation of MSW and material recovery as ash is incorporated into the product) $[3,9,11]$. In this frame, the aim of the present article is to preliminarily analyse the effects that the introduction of the principles of circular economy can have on the occupational risk in the sector of MSW management. The reference scenario chosen for this article concerns an Italian town that reached a very high efficiency of selective collection (SC) and where a lot of data have been generated in the last years to characterize the content of MSW. Since 2015, the town, has to modify a few criteria of MSW management in order to fully comply with the vision of EU [12].

\section{Materials and methods}

The methodology adopted in the present article was based on the following steps. For each stream of MSW that is presently source separated, details on the rate of source separated collection, on destination and on material recovery were collected (specifically food waste and green waste, paper and cardboard, plastics, metals, glass, composite materials, textiles, expired medicaments, exhausted batteries and other).

This detailed scenario was analysed concerning two aspects:

- potential improvements of present efficiency of source separation

- new possible initiatives on source separated streams and their treatment (e.g. diapers).

Concerning the first point, additional modifications to the present approach were analysed in order to maximize material recovery, optimize energy recovery and minimize landfilling. Consequences of this re-organization of the sector were discussed in terms of occupational risk and economic impact.

\section{Results and discussion}

Data collected in the case study showed a high level of organization of the separation and treatment of the materials present in the MSW. Specifically, the valorisation of food waste (Table 1) and green waste has reached very high levels of source separation rate (presently beyond $85 \%$ ), of biogas generation (around $170 \mathrm{~m}^{3} / \mathrm{t}$ of food waste fed in the main plant) and of compost quality (easily sold). The economic value of compost is not relevant when compared to the other income issues (tariff at the gate and energy sold). However, it must be seen as an avoided cost compared to the landfilling scenarios.

Improvements in agreement with the principles of circular economy are expected to be related to the addition of a plant for biomethane extraction from biogas (to be fed as a highquality product into the existing natural gas grid). This modification will introduce an industrial reactor in a plant having a medium level of technology to be operated. Occupational risk will change but that can be correctly managed thanks to automation and remote control. This approach is supported by new public incentives set to move the sector from small scale local co-generation from biogas to this new vision. However, without public incentives the initiative could not be economically sustainable. An additional option can be based on the extraction of $\mathrm{CO}_{2}$ from the off gas remaining after biogas upgrading (that allows extraction of methane). In this case the fate of the extracted $\mathrm{CO}_{2}$ could be for sequestration initiatives or for industrial uses. In Italy, the sector seems to be not yet ready for supporting this enhanced approach. This is demonstrated by the extremely reduced cases implemented on real scale until now. The problems are basically related to the cost; indeed, from the technical point of view the extraction of $\mathrm{CO}_{2}$ from the off gas can be performed by a membrane that does not create significant additional risks. 
Table 1. Targets achievement.

\begin{tabular}{|c|c|c|c|c|}
\hline Fractions & Target & Percentage & Deadline & Status \\
\hline $\begin{array}{c}\text { Residual } \\
\text { MSW }\end{array}$ & Landfilling & $5 \%$ & 2030 & Achieved \\
\hline $\begin{array}{c}\text { Packaging } \\
\text { waste }\end{array}$ & Recycling & $\begin{array}{c}>70 \% \\
>80 \%\end{array}$ & $\begin{array}{c}2025 \\
2030\end{array}$ & $\begin{array}{c}\text { Achieved } \\
\text { Achieved }\end{array}$ \\
\hline Textile & $\begin{array}{c}\text { Source } \\
\text { separation }\end{array}$ & - & 2020 & Achieved \\
\hline Oils & $\begin{array}{c}\text { Source } \\
\text { separation and } \\
\text { regeneration }\end{array}$ & - & 2025 & Achieved \\
\hline $\begin{array}{c}\text { Hazardous } \\
\text { MSW }\end{array}$ & $\begin{array}{c}\text { Source } \\
\text { separation }\end{array}$ & - & 2020 & Achieved \\
\hline $\begin{array}{c}\text { Organic } \\
\text { waste }\end{array}$ & $\begin{array}{c}\text { Source } \\
\text { separation }\end{array}$ & $>80 \%$ & - & Achieved \\
\hline
\end{tabular}

Table 2. Options chosen for the valorisation of SC streams

\begin{tabular}{|c|c|}
\hline Fractions & Adopted solution \\
\hline Organic fraction & Anaerobic digestion \\
\hline Green waste & Composting \\
\hline Paper and cardboard & Recycling \\
\hline Plastic & Recycling \\
\hline Glass & Recycling \\
\hline Metals & Recycling \\
\hline Wood & Recycling \\
\hline Textile & Recycling \\
\hline WEEE & Material recovery \\
\hline Inert & Material recovery \\
\hline Sweeping & Sand cleaning \\
\hline
\end{tabular}


Another issue concerns the source separation of diapers for material recovery. This is a target of the Municipality to increase SC efficiency and material recovery. The interest for this fraction of MSW bases on its high presence in the RMSW (around 28\%) as a result of source separation of other fractions. The overall amount of diapers makes interesting the assessment of the feasibility of source separation aimed to material recovery: plastic and cellulosic material are components of diapers.

The logistic aspects of source separation and collection of this stream have been already analysed. Specifically, as the town has already activated a kerbside collection system, there is the need to add another bin at user level. The technical and social analyses of that gave as potential solution the use of a bag to be exposed when needed, with the characteristics of reporting only a small writing for the operators that get off the bags.

Results from a pilot plant for the treatment of this stream are interesting but affected by the classification of the outputs; indeed, the outputs are still considered waste and not yet secondary products. This is a general problem for enhanced solutions of material recovery from waste. The aspect of unfavourable classification of the outputs has important consequences on the economic sustainability of the approach.

For this reason, the adoption of this additional SC has been postponed. Occupational risks have been analysed to obtain the authorization to operate the plant. The problems to be managed are related to the hygienic risk from used diapers that stay on the territory a few days before being processed; indeed, considering the amount of material to be collected, it is not economically viable a solution based on a daily collection.

The improvement of the efficiency of source separation of conventional streams (Table 2) could be concentrated on the communication to the citizens on the importance of putting correctly the waste in the light packaging bag. This is related to two matters:

- incorrect deliveries increase the cost of MSW management because the anomalous bags are considered of no value in the market of recycling materials;

- efficiency means not only raw source separation but also real material recovery rate; this parameter is going to be more and more used in the sector for a correct vision of the approach.

Moreover, there is room for making the treatment of the residual MSW more coherent with the principles of the Circular Economy (CE) as the adopted solution is flexible, thus suitable for modifications. Basically, the rate of residual MSW that is still landfilled (after pre-treatment) should be moved to SRF production and exploitation in cement factories as ash can be included in the final product (cement).

Finally, also the residues from the treatment of SC could have a better management. In Table 3 the impurities that characterise the source separated fractions are pointed out (rounded to the unit).

The efficiency guaranteed by the citizens for the quality of the source separated biodegradable fractions is one of the best in Italy, thus improvements to be expected are limited. On the contrary, the need to improve the approach for light packaging is clear (specifically plastics and metals). However, in this case the separation can be improved possibly by introducing manual sorting as refining stage. That imply an increase of the occupational risk. 
Table 3. Percentages of impurities in the source separated streams.

\begin{tabular}{|c|c|}
\hline Fractions & Impurities \\
\hline Organic fraction & $3 \%$ \\
\hline Green waste & $3 \%$ \\
\hline Paper and cardboard & $15 \%$ \\
\hline Plastic & $30 \%$ \\
\hline Glass & $5 \%$ \\
\hline Metals & $20 \%$ \\
\hline Wood & $5 \%$ \\
\hline Textile & $0 \%$ \\
\hline WEEE & $0 \%$ \\
\hline Inert & $0 \%$ \\
\hline Sweeping & $40 \%$ \\
\hline
\end{tabular}

\section{Conclusions}

The modification of the approach in a context where high efficiency results have been already reached seems to slightly modify the overall occupational risk. Criticalities seems to be related to the introduction of SC of diapers and on the addition of manual sorting for refining source separated streams of light packaging. In the first case, hygienic risks involve also the SC actions. In the second case the additional risk depends strongly on the content of the source separated stream.

This research was supported by Act 211 Government of the Russian Federation, contract № 02.A03.21.0006. 


\section{References}

1. M.D. Noussan, R. Robertovic, B.I. Nastasov, J Loss Prevent Proc 11, 650-657 (2018) A. Pires, G. Martinho, 2019. Waste Manag 95, 298-305 (2019)

2. J. Malinauskaite, H. Jouhara, D. Czajczyńska, P. Stanchev, E. Katsou, P. Rostkowski, R.J. Thorne, J. Colón, S. Ponsá, F. Al-Mansour, L. Anguilano, R. Krzyżyńska, I.C. López, A. Vlasopoulos, N. Spencer, Energy 141, 2013-2044 (2017)

3. E.C. Rada, L.I. Cioca, G. Ionescu, MATEC Web of Conferences, 121, 05006 (2017)

4. M. Grosso, M. Niero, L. Rigamonti, Waste Manag Res, 35(8), 793-794 (2017)

5. E.C. Rada, L.I. Cioca, Energy Procedia, 119, $72-85$ (2017)

6. A. Van Schaik, M.A. Reuter, World of Metallurgy - ERZMETALL, 69(4), 201-216 (2016)

7. N. Gregson, M. Crang, S. Fuller, H. Holmes, Econom Society, 44(2), 218-243 (2015)

8. C. Ingrao, N. Faccilongo, L. Di Gioia, A. Messineo, A., J Clean Prod, 184, 869-892 (2018).

9. D. Arina, R. Bendere, Environ Res Eng Manag, 74(1), 43-49 (2018)

10. M. Ragazzi, M. Maniscalco, V. Torretta, N. Ferronato, E.C. Rada, Energy Procedia, 119, 602$614(2017)$

11. E.C. Rada, M. Ragazzi, V. Torretta, G. Castagna, L. Adami, L.I. Cioca, AIP Conference Proceedings, 1968, 030050 (2018)

12. www.comune.trento.it (last access: July $30^{\text {th }} 2019$ ) 